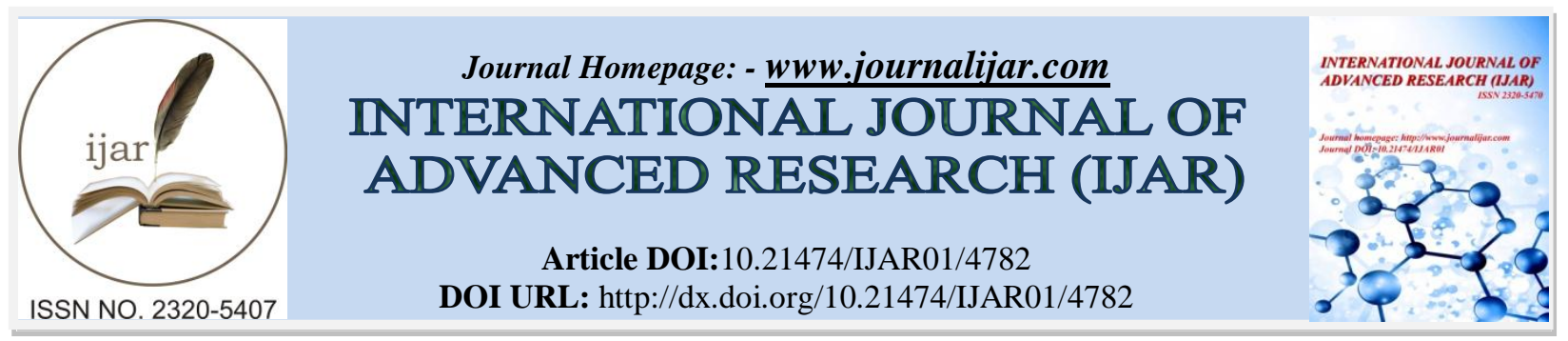

RESEARCH ARTICLE

\title{
IRON CONTENT IN RICE UNDER DIFFERENTIAL IRON TREATMENT.
}

\section{Ritu Saini ${ }^{1}$, Harnek Singh Saini ${ }^{2}$, Anjali Dahiya ${ }^{1}$ and Sunita Jain ${ }^{3}$.}

1. Department of Chemistry and Biochemistry, CCS Haryana Agricultual University, Hisar, 125004

2. Department of Biotechnology Engineering, University Institute of Engineering and Technology Kurukshetra University, Kurukshetra-136119, India.

3. Department of Molecular Biology, Biotechnology and Bioinformatics, CCS Haryana Agricultual University, Hisar- 125004, India.

\section{Manuscript Info}

\section{Manuscript History}

Received: 8 May 2017

Final Accepted: 10 June 2017

Published: July 2017

Key words:-

Rice, iron, genotypes, grains, soil

\section{Abstract}

In the present investigation, iron content changes in root and shoot tissues of six rice genotypes (Govind, Super, HKR120, Pusa1121, HBC19 and Palman579) differing in grain iron concentration (35- 400 $\mu \mathrm{g} / \mathrm{g}$ ) were studied in response to varied iron concentrations at vegetative and reproductive stages. Plants were grown in pots in the net house and treated twice with Yoshida solution containing different iron concentrations $(0,0.1 \mathrm{mM}, 0.5 \mathrm{mM}$ EDTA-Fe II). Fe content in roots, shoots and grains increased with increase in Fe concentration. Roots of HBC19 and Palman579 contained higher iron while the per centage increase in iron uptake was higher in roots of Govind and Super. Lower and upper shoots of PUSA1121 showed highest iron. Highest iron in dehusked grains was recorded in Palman579 followed by HBC19, PUSA1121, HKR120, Super and Govind. Thus, with increase iron in medium the iron content was consistently increase in all tissues and soil but the per cent increase depends on genotypic variation.

Copy Right, IJAR, 2017,. All rights reserved.

\section{Introduction:-}

Rice (OryzasativeL.) is one of the agronomically and nutritionally important cereal crops. It is a major source of food for more than 2.7 billion people on a daily basis and is planted on about one-tenth of the earth's arable land. It is the single largest source of food energy to half of the humanity in the world, most of them in developing countries (Ammar, 2007). Around 3 billion people (mostly in Asia) depend on rice for 35 to 59 per cent of their caloric intake. However, rice is a poor source of micronutrients, including iron. Iron (Fe) is an essential micronutrient that plays critical role in metabolic processes such as DNA synthesis, respiration and photosynthesis in all living organisms. Further, many metabolic pathways are activated by Fe, and it is a prosthetic group constituent of many enzymes. In nature, Fe occurs in abundance and ranks fourth among all elements on earth's surface. Still, its availability to plants is reduced, once this element is in the form of hydrated oxides, which can limit plant productivity and biomass production. On the other hand, in high concentrations, this essential micronutrient for the plants can become a toxic agent, also increasing the environmental contamination. The balance of Fe should be strictly maintained, because its deficiency and as well as its toxicity affect the physiological process of plants. Fe is the third most limiting nutrient for plant growth and metabolism, primarily due to the low solubility of the oxidized ferric form in aerobic environments (Samaranayke et al., 2012). In response to Fe deficiency, plants induce either reduction or chelation- 
based mechanisms to enhance Fe uptake from the soil (Onagaet al., 2016). Iron translocation and homeostasis in rice has been well studied and several genes, most of which are transcriptionally regulated in response to Fe availability, are known to coordinate Fe uptake, translocation and storage in various tissues/compartments of the plant (Kobayashi and Nishizawa, 2012). Heavy metal toxicity in agricultural soils is a serious concern for quality food production (Adreeset al., 2015; Ali et al., 2015; Rizwanet al., 2016). Iron (Fe) nutrition in plants is highly regulated in order to supply amounts sufficient for optimal growth while preventing deleterious effects. The objective of the present study is to investigate the effect of different iron treatments on the iron content of the rice plant and soil.

\section{Materials and Methods:- \\ Plant material:-}

The experimental material comprised of fifteen rice varieties viz. Palman579, HKR95-157, HKR95-130, HBC19, HKR47, PS 4, HKR120, PUSA1121, IR64, IR72, Jaya, Govind, Azucena, PAU201 and Super. Seeds of the ten rice varieties i.e HBC19, HKR47, PS4, IR64, Jaya, Govind, HKR120, Azucena, PAU201 and PUSA1121 were procured from Department of Genetics and Plant breeding, Rice Research Station, Kaul and seeds of Palman579, HKR95-157, HKR95-130, IR72 and Super were obtained from Department of Molecular Biology, Biotechnology and Bioinformatics, CCS HAU (Haryana).

\section{Raising of crops and treatments:-}

Grain iron (Fe) content of fifteen rice varieties was analyzed by method of Lindsey and Norwell (1978) and based on the data, six rice varieties, two each with low grain iron (Govind, Super), medium grain iron (HKR120, PUSA1121) and high grain iron (HBC19, Palman579) content were selected for this study. The crop was raised during kharif seasons of 2013-2014 and 2014-2015 in net house of Department of Chemistry and Biochemistry, CCS HAU, Hisar. Seeds of all rice varieties were sown directly in pots at 2-3 cm depth in light textured (loamy) soil with standard conventional cultivation practices and the pots were divided in three sets after 20 days of sowing and following treatment were given: One set was given Yoshida nutrient medium without Fe (0 mM EDTA-Fe(II)). Second set was given Yoshida nutrient medium with $0.1 \mathrm{mM}$ EDTA-Fe(II)) concentration. Third set was given Yoshida nutrient medium with high Fe concentration (0.5 mM EDTA-Fe (II)).

\section{Estimation of iron content in different plant tissues (roots, shoots and grains):-}

Iron content of root, lower shoot, upper shoot (leaves) was estimated at vegetative and reproductive stages and Fe content of grains was analyzed at maturity in all the six varieties of rice by using Atomic Absorption Spectrophotometery. The samples were prepared by dehulling manually. One gram oven dried ground dehusked (brown) seed samples were collected in a $150 \mathrm{ml}$ conical flask. To this, $30 \mathrm{ml}$ diacid mixture $\left(\mathrm{HNO}_{3}: \mathrm{HClO}_{4} ; 5: 1 \mathrm{v} / \mathrm{v}\right)$ was added and kept overnight. Next day, it was digested by heating till clear white precipitates settled down at the bottom. The crystals were dissolved by diluting in double distilled water. The contents were filtered through Whatman No. 42 filter paper. The filtrate was made to $50 \mathrm{ml}$ with double distilled water. The acid digested samples were used for the determination of iron content by Atomic Absorption Spectrophotometer 2380, Perkin Elmer (USA) according to the method of Lindsey and Norwell (1978). Calibrations were done with the standard solutions of 1,3 and 5 ppm iron.

\section{Estimation of iron content of soil samples:-}

Iron content of soil was studied at vegetative and reproductive stages by DTPA soil test (Lindsay and Norvell, 1978). The extractant (DTPA reagent) consisted of $0.005 M$ DTPA (diethylenetriaminepentaacetic acid), $0.1 M$ TEA (triethanolamine), and $0.01 \mathrm{M} \mathrm{CaCl}_{2}$, with a $\mathrm{pH}$ of 7.3. To prepare 1 liter of DTPA reagent, dissolved $1.96 \mathrm{~g}$ DTPA, $13.3 \mathrm{~g} \mathrm{TEA}$ and $1.47 \mathrm{~g} \mathrm{CaCl}_{2} 2 \mathrm{H}_{2} \mathrm{O}$ in approximately $50 \mathrm{ml}$ of distilled water. Allowed sufficient time for the DTPA to dissolve, and diluted to approximately 1 liter. Adjusted the $\mathrm{pH}$ to $7.30 \pm 0.05 \mathrm{with} 4 \mathrm{ml}$ of $1 \mathrm{NHC} 1$ while stirring and made the final volume 1 liter. Ten grams of oven dried soil was placed in $125 \mathrm{ml}$ conical flask and $20 \mathrm{ml}$ of DTPA reagent was added to this. Each flask was covered with stretchable Parafilm and kept overnight which was followed by shaking for 2 hours on shaker. The suspensions were filtered through Whatman no. 42 filter paper. The filtrates were analyzed for Fe using Atomic Absorption Spectrophotometer 2380, Perkin Elmer (USA).

The data obtained in the present investigation was subjected to analysis of variance (ANOVA) technique and thus analyzed according to two/three factorial completely randomized designs. The critical difference value at $5 \%$ level was used for making comparison among various rice varieties grown under different iron treatments and at all the stages. OP stat was used to analyze experimental results statistically. 


\section{Results:-}

Iron content in grains $(\mu \mathrm{g} / \mathrm{g}$ dry wt.) of fifteen rice varieties:-

Significant variation in grain iron content was observed in 15 rice varieties (Table 1.1). Fe content ranged between 62.45 to $439.53 \mu \mathrm{g} / \mathrm{g}$ dry wt. Govind and Super had considerably lowgrain Fe content $(36.75$ and $38.18 \mu \mathrm{g} / \mathrm{g}$ dry wt.), while HKR95-157, HKR95-130, Palman579 and HBC19 had high grain Fe (>180 $\mu \mathrm{g} / \mathrm{g}$ dry wt.). Other rice varieties had grain Fe content ranged between 51 to $180 \mu \mathrm{g} / \mathrm{g}$ dry wt. and were considered as moderate Fe content varieties.

Table 1.1:- Iron content in grains $(\mu \mathrm{g} / \mathrm{g}$ dry wt.) of fifteen rice varieties.

\begin{tabular}{|c|l|c|}
\hline Sr. No. & Varieties & Fe content in grains $(\boldsymbol{\mu g} / \mathbf{g})$ \\
\hline 1 & Palman579 & $403.38 \pm 0.82$ \\
\hline 2 & HKR95-157 & $439.53 \pm 0.47$ \\
\hline 3 & HKR95-130 & $411.61 \pm 0.54$ \\
\hline 4 & HBC19 & $207.58 \pm 0.48$ \\
\hline 5 & HKR47 & $98.24 \pm 0.45$ \\
\hline 6 & PS4 & $78.92 \pm 0.49$ \\
\hline 7 & HKR120 & $60.47 \pm 0.75$ \\
\hline 8 & Pusa1121 & $89.70 \pm 0.80$ \\
\hline 9 & IR64 & $62.45 \pm 0.76$ \\
\hline 10 & IR72 & $68.36 \pm 0.25$ \\
\hline 11 & Jaya & $174.32 \pm 0.21$ \\
\hline 12 & Govind & $36.75 \pm 0.26$ \\
\hline 13 & Azucena & $78.60 \pm 0.52$ \\
\hline 14 & PAU201 & $73.94 \pm 0.14$ \\
\hline 15 & Super & $38.18 \pm 0.13$ \\
\hline
\end{tabular}

Iron content in different plant tissues:-

Iron content of root, lower shoot, upper shoot was analyzed at vegetative and reproductive stages in the six selected rice varieties grown under $0 \mathrm{mM}$ EDTA-Fe(II) (control), $0.1 \mathrm{mM}$ EDTA-Fe(II) (normal) and $0.5 \mathrm{mM}$ EDTA-Fe(II) (high) Fe treatments by using Atomic Absorption Spectrophotometer. Fe content of grains was studied at maturity.

\section{Iron content in roots $(\mu \mathrm{g} / \mathrm{g}$ dry wt.):-}

Increase in $\mathrm{Fe}$ content was observed in root tissues of all six varieties with increasing $\mathrm{Fe}$ concentration. At vegetative stage, the root Fe content ranged from 421.90 (Govind) to $802.07 \mu \mathrm{g} / \mathrm{g}$ dry wt. (HBC19) at $0 \mathrm{mM} \mathrm{Fe}$ treatment (Fig. 1.1 A). 18.30\% (Palman579) to 65.31\% (Govind) increase in Fe content at $0.1 \mathrm{mM} \mathrm{Fe}$ treatment whereas $31.54 \%$ (Palman579) to $106.82 \%$ (Govind) increase at $0.5 \mathrm{mM}$ Fe treatment (high) was observed as compared to $0 \mathrm{mM}$ treatment. At reproductive stage also higher increase 57.19\% (0.1 mM Fe-EDTA) and 97.65\% $(0.5 \mathrm{mM}$ Fe-EDTA) in iron content was observed in roots of Govind while minimum increase of $19.72 \%$ and $35.36 \%$ at $0.1 \mathrm{mM}$ and $0.5 \mathrm{mM}$ Fe treatments respectively was observed in roots of Palman579 (Fig. 1.1 B). Though the Fe content was higher in roots of $\mathrm{HBC} 19$ and Palman579 at all Fe at both vegetative and reproductive stages but the magnitude of increase in iron content was more in roots of Govind and Super with increased Fe concentrations. 


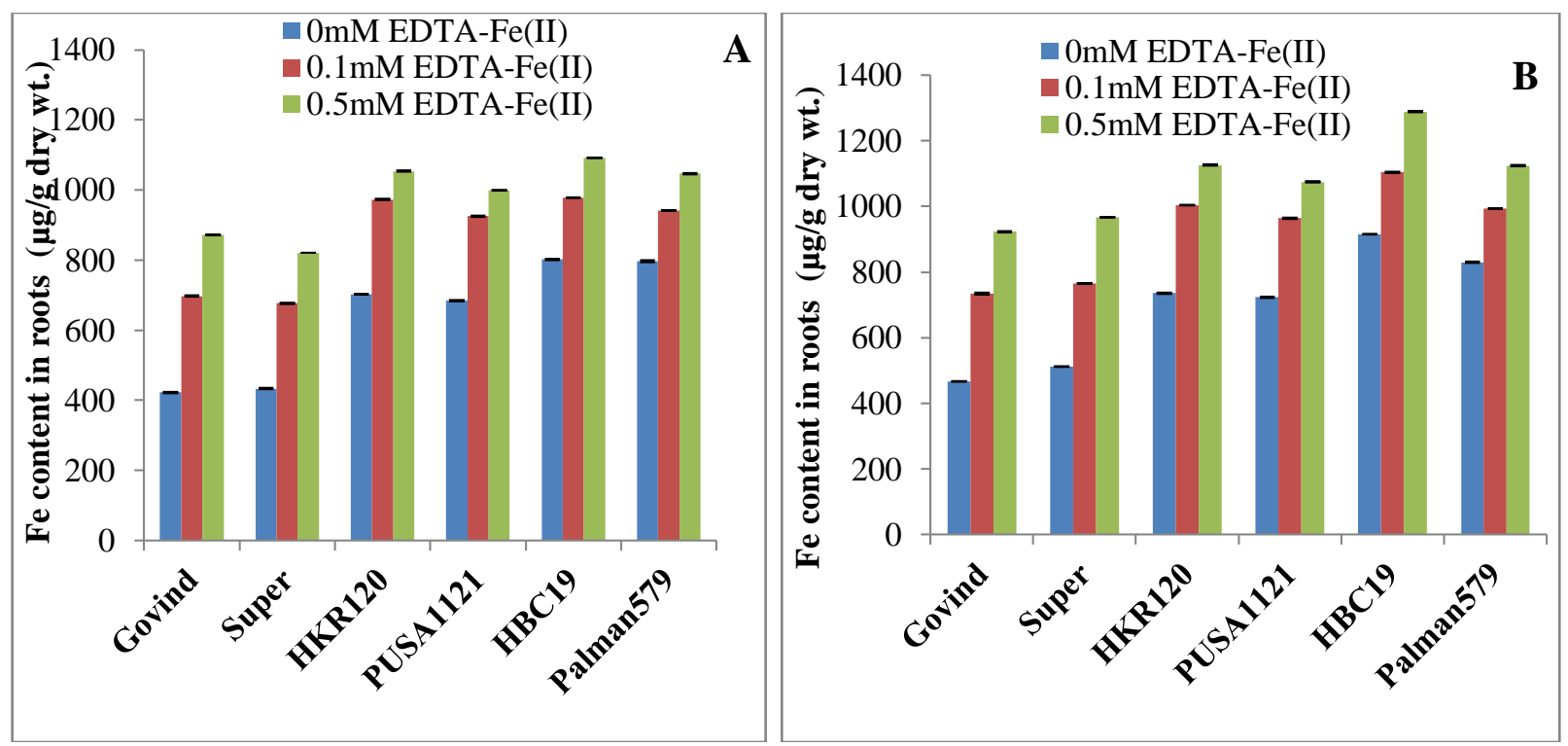

Figure 1.1:-Variation in iron content in response to iron treatments in roots of six rice varieties at vegetative (A) and reproductive (B) stages [The bars denote $\pm \mathrm{SE}$ ]

Iron content in lower shoots $(\mu \mathrm{g} / \mathrm{g}$ dry wt.):-

All six rice varieties showed an increase in iron content in lower shoots with increasing Fe treatment at both the stages. At vegetative stage, higher iron content was observed in lower shoots of PUSA1121 $(679.73,872.50 \mu \mathrm{g} / \mathrm{g}$ dry wt.) and $\mathrm{HBC} 19(667.20,830.90 \mu \mathrm{g} / \mathrm{g}$ dry wt.) at $0.1 \mathrm{mM}$ and $0.5 \mathrm{mM}$ Fe treatment, respectively. The per cent increase was observed maximum in PUSA1121 and minimum in Govind at both the treatments. Similar, results were found at reproductive stage, the increase in Fe content ranged from 11.25 to $46.75 \%$ at $0.1 \mathrm{mM}$ Fe treatment and 24.41 to $88.74 \%$ at $0.5 \mathrm{mM}$ Fe treatment in Govind and PUSA1121, respectively. Palman579 showed differential behavior in increase in Fe content in lower shoot at both the developmental stages, the increase was 36.17 and $65.13 \%$ at vegetative stage while it was much lower 20.05 and $43.61 \%$ at reproductive stage at $0.1 \mathrm{mM}$ and $0.5 \mathrm{mM}$ Fe treatment, respectively (Fig. 1.2 A and B).

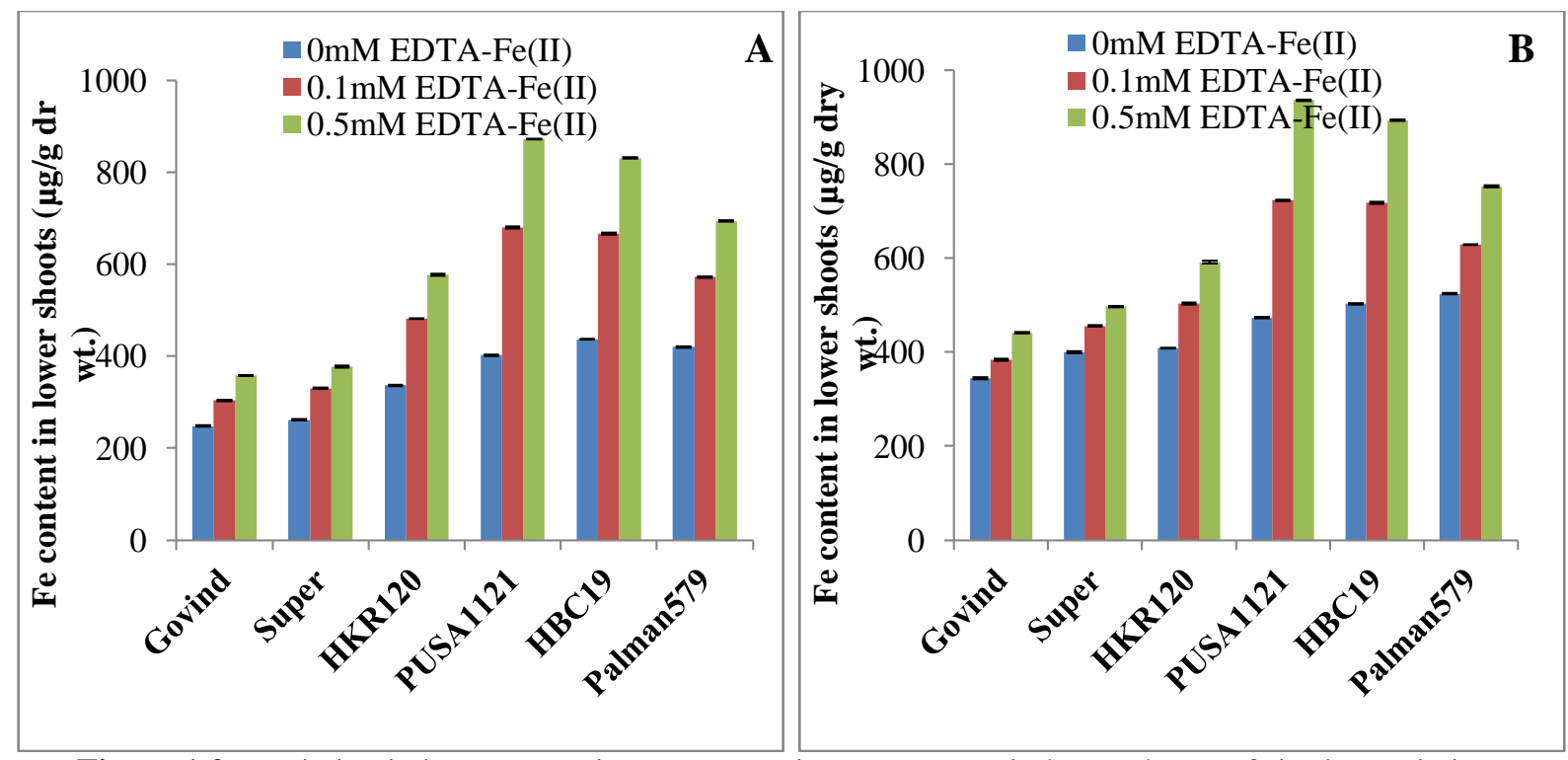

Figure 1.2:-Variation in iron content in response to iron treatments in lower shoots of six rice varieties at vegetative (A) and reproductive (B) stages [The bars denote \pm SE]. 


\section{Iron content in upper shoots $(\boldsymbol{\mu g} / \mathrm{g}$ dry wt.):-}

As depicted in Fig. 1.3 (A), at vegetative stage the iron content in upper shoots ranged from $96.30 \mu \mathrm{g} / \mathrm{g}$ dry wt. (Govind) to $341.40 \mu \mathrm{g} / \mathrm{g}$ dry wt. (PUSA1121) at $0 \mathrm{mM}$ Fe treatment (control). All the six rice varieties showed an increase in iron content in the upper shoots with increasing Fe treatments. Maximum iron content of $654.79 \mu \mathrm{g} / \mathrm{g} \mathrm{f}$. wt. was recorded in PUSA1121 at $0.5 \mathrm{mM}$ Fe concentration whereas minimum (130.17 $\mu \mathrm{g} / \mathrm{g} \mathrm{f}$. wt.) in Govind. PUSA1121, HBC19 and Palman579 not only had high iron content under the control conditions (0 mM Fe treatment) but also had higher increase in iron content with increasing iron concentration $(0.1$ and $0.5 \mathrm{mM} \mathrm{Fe})$ as compared to HKR120, Super and Govind.

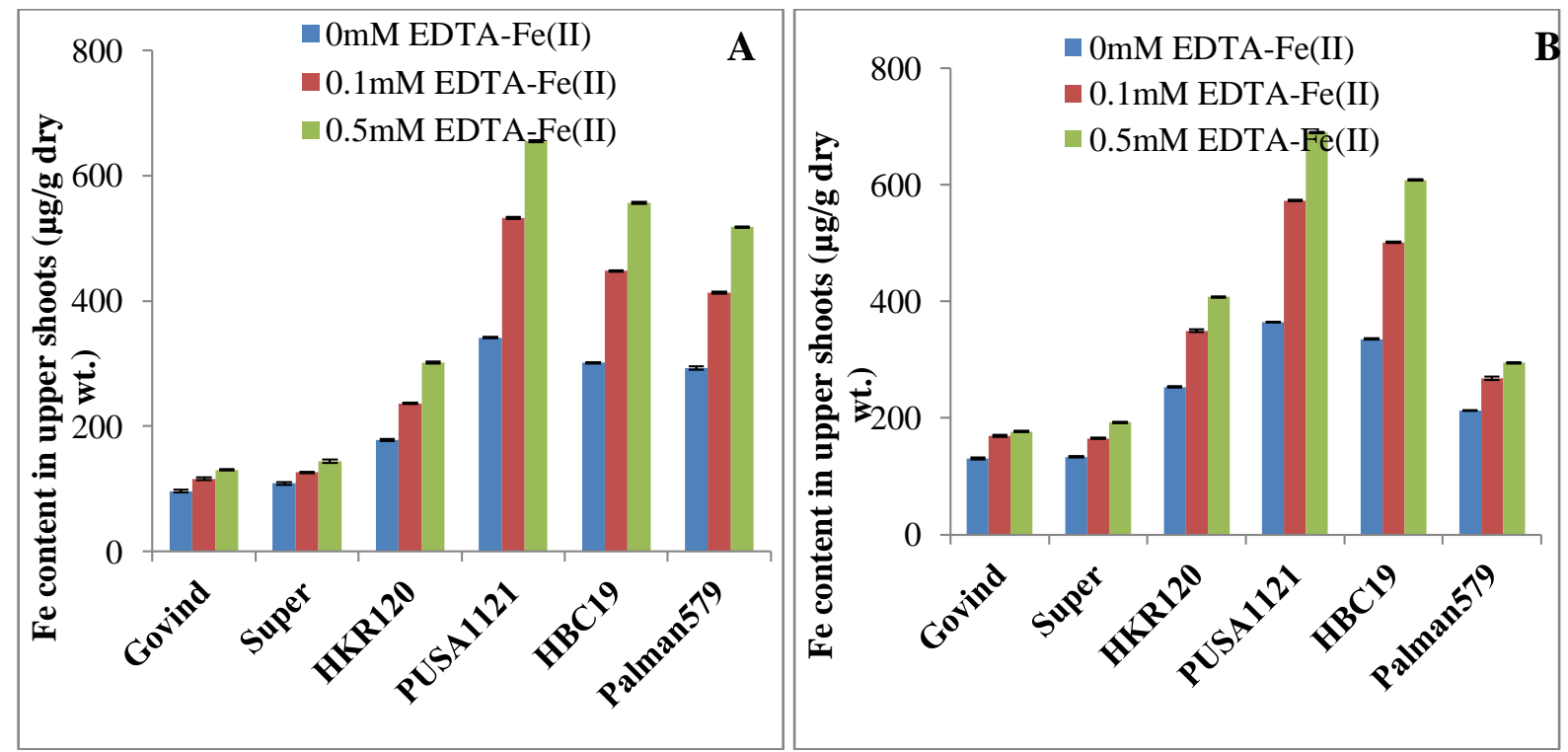

Figure 1.3:-Variation in iron content in response to iron treatments in upper shoots of six rice varieties at vegetative (A) and reproductive (B) stages [The bars denote $\pm \mathrm{SE}$ ]

Similar pattern was observed at reproductive stage by all the varieties except Palman 579 which showed a lower level increase in shoot iron content with higher $(0.5 \mathrm{mM})$ Fe treatment. Increase in Fe content in the upper shoots ranged from 23.89 (Super) to 57.19\% (PUSA1121) and 35.64 (Govind) to 89.13\% (PUSA1121) at $0.1 \mathrm{mM}$ and 0.5 $\mathrm{mM}$ Fe treatments (Fig. 1.3 B). In Palman579, the increase in iron content at $0.5 \mathrm{mM}$ Fe concentration was $76.90 \%$ and $38.40 \%$ at vegetative and reproductive stages, respectively.

Iron content in grains $(\mu \mathrm{g} / \mathrm{g}$ dry wt.):-

Iron content in dehusked rice grains varied significantly between 27.63 (Govind) - $235.37 \mu \mathrm{g} / \mathrm{g}$ (Palman579) under control conditions (no additional Fe added in soil) (Fig. 1.4). Grain iron content increased linearly with increasing iron treatments in all the six varieties. The maximum increase in iron content was observed in Palman579 (65.26\% and $92.17 \%$ ) followed by $\mathrm{HBC} 19$ (48.71\% and $79.65 \%)$ while the lowest increase was noticed in Govind (13.39\% and $26.06 \%$ ) at $0.1 \mathrm{mM}$ and $0.5 \mathrm{mM} \mathrm{Fe}$ treatments respectively, as compared to the control treatment. At $0.5 \mathrm{mM} \mathrm{Fe}$, grain iron content ranged from 34.83 (Govind) to $452.34 \mu \mathrm{g} / \mathrm{g}$ (Palman579). At all the Fe treatments, significantly higher grain Fe content were found in Palman579 and HBC19. 


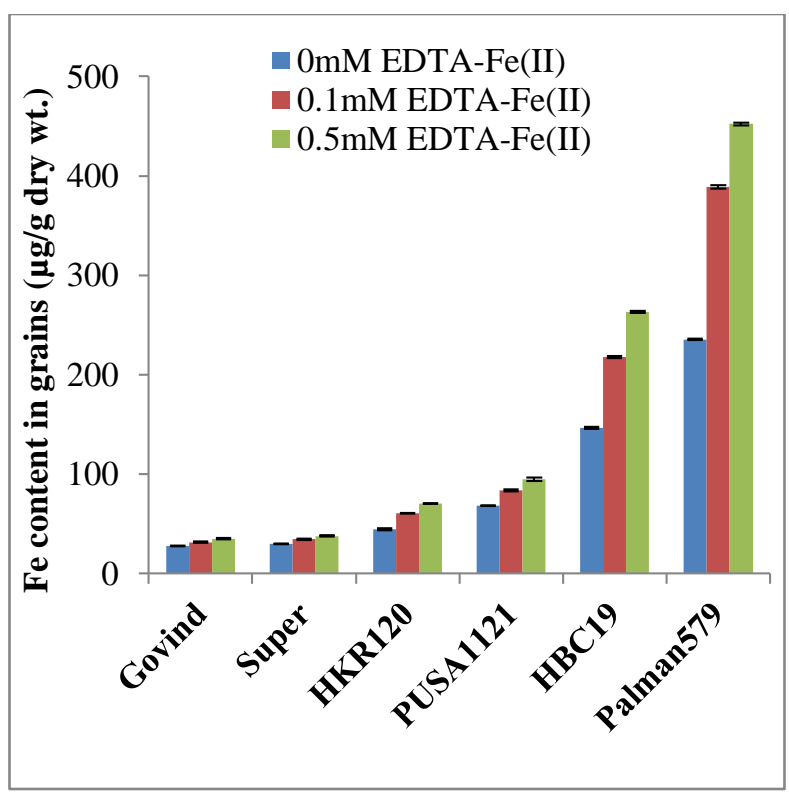

Figure 1.4:-Variation in iron content in response to iron treatments in grains of six rice varieties at maturity [The bars denote $\pm \mathrm{SE}]$.

Iron content in soils $(\mu \mathrm{g} / \mathrm{g}$ dry wt.):-

At vegetative stage, the Fe content in soil ranged from 5.35 (Govind) to $6.20 \mu \mathrm{g} / \mathrm{g}$ dry wt. (Palman579) at $0 \mathrm{mM} \mathrm{Fe}$ treatment. At $0.1 \mathrm{mM}$ Fe treatment, 20.54\% (Govind) to 30.95\% (Palman579) whereas at $0.5 \mathrm{mM}$ Fe treatment, $38.08 \%$ (Govind) to $53.73 \%$ (Palman579) increase in soil iron content were recorded compared to the control (0 $\mathrm{mM}$ iron) treatment (Fig. 1.5 A). In the control with no additional $\mathrm{Fe}$, maximum $\mathrm{Fe}$ content was recorded in the Palman579 soil (5.68 $\mu \mathrm{g} / \mathrm{g}$ dry wt.) and minimum in the soil of Govind $(4.73 \mu \mathrm{g} / \mathrm{g}$ dry wt.) at reproductive stage. The per cent increase in soil iron content varied from 23.01 (Super) to 35.83 (Palman579) at $0.1 \mathrm{mMFe}$ treatment. At $0.5 \mathrm{Fe}$ treatment, soils of Govind and Palman579 recorded minimum (36.83\%) and maximum (52.51\%) increase in soil Fe content, respectively (Fig. 1.5 B). Iron content of soil was also analyzed at start of experiment which was $6.71 \mu \mathrm{g} / \mathrm{g}$ dry wt.

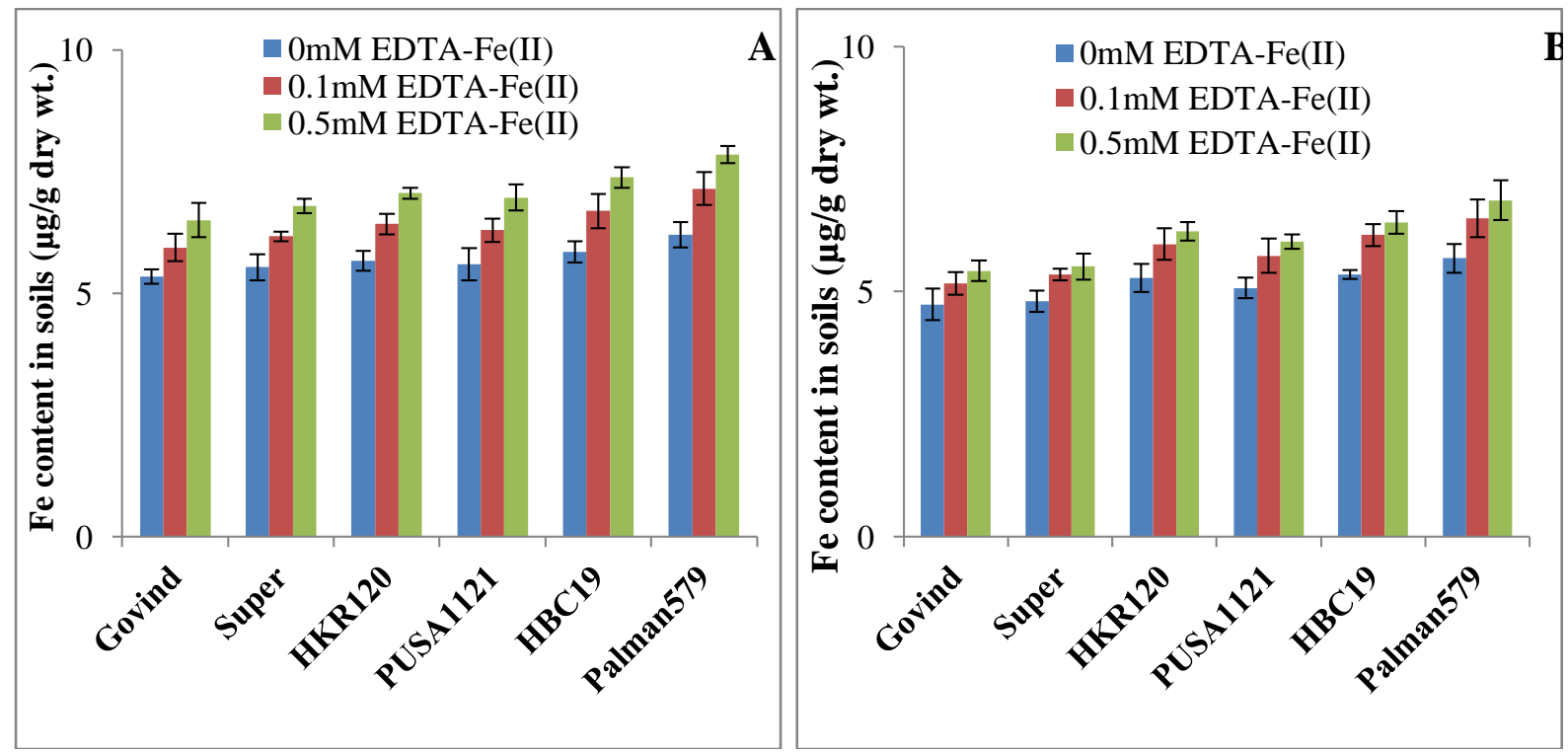

Figure 1.5:-Variation in soil iron content in response to iron treatments at vegetative (A) and reproductive (B) stages [The bars denote $\pm \mathrm{SE}$ ] 


\section{Discussion:-}

In the present study, Fe content in different plant tissues (roots, lower shoots, upper shoots and grains) increased with increase in $\mathrm{Fe}$ concentration in all the six rice varieties at both vegetative and reproductive stages. Iron uptake was higher in the roots of low Fe grain content varieties i.e. Govind and Super at both the stages (Fig. 1.1). In contrast, transport of Fe from root to lower shoot and from lower shoot to upper shoot was higher in medium and high grain varieties PUSA1121 and HBC19 (Fig. 1.2; 1.3). Palman579 grains contain maximum Fe (Fig. 1.4). Likewise, Fe content in soil increased with increase in Fe concentration at both the stages (Fig. 1.5). The results are similar to Shi et al. (2016) observations where the Fe content in rice significantly increased after the exogenous application of ferrous sulfate $\left(\mathrm{FeSO}_{4}\right)$. Concomitant with our findings, increased accumulation of Fe in roots and shoots has been reported with an increase in $\mathrm{FeSO}_{4}$ concentration in rice (Kabir et al., 2016) and soybeans (Pooladvand et al., 2012). Panda et al. (2016) noticed that Fe concentration of the flag leaf of rice cultivars increased with increase in Fe level in the culture medium (from $0.05 \mathrm{mg}$ to $15 \mathrm{mg} \mathrm{L}^{-1}$ ). Similarly, Mehraban et al. (2008) reported that $\mathrm{Fe}$ content in roots and shoots of rice plants increased significantly by increment of Fe concentration in the medium. The primary site of Fe accumulation was roots but less amount of Fe was translocated to upper part of the plant. The exogenous Fe application also improved the nutritional quality of rice. The accumulation of the metal in the plant was proportional with its concentration in the medium and registered higher values in roots than shoots which coincides with earlier studies as obtained for $\mathrm{Hg}, \mathrm{Cu}, \mathrm{Cd}, \mathrm{Cr}$ (Gupta et al., 1994; Sinha et al., 1996). High iron accumulation in roots in all rice varieties with excess of iron sulfate may be due to the maintenance of solubility and availability of iron in its divalent form (Fang et al., 2001; Sahrawat, 2005). The addition of EDTA may have also favoured the bioavailability by minimizing reoxidation of iron (Taylor et al., 1984; Snowden and Wheeler, 1995).

It should be noted that while Palman579 grains had exceptionally higher iron content, HBC19 also had relatively higher iron content compared to the other indica rice varieties. Similar high grain iron in Palman579 and HBC19 has also been reported by Brar et al. (2011). Rice genotypes having contrasting grain Fe concentration had been found to have different levels of physiological Fe concentration in different plant parts (Panda, 2010). Irmak et al. (2008) studied theeffects of Fe content of soils on the Fe content of leaf and grain samples of wheat and reported that Fe content of the leaf and grain samples was directly correlated with the Fe content of the soil while, there was an inverse relation between iron content of grain and iron content of leaf.

\section{Conclusion:-}

Iron treatment increases the iron content in soil and all rice tissues while the per cent increase depends on genotypic variation.

\section{References:-}

1. Brar, B., Jain, S., Singh, R. and Jain, R.K. (2011) Genetic diversity for iron and zinc content in a collection of 220 rice (Oryza sativa L.) genotypes. Ind. J. Genet. Plant Breed. 71(1), 67-73.

2. Fang, W.C., Wang, J.W., Lin, C.C. and Kao, C.H. (2001) Iron induction of lipid peroxidation and effects on antioxidative enzyme activities in rice leaves. Plant Growth Regulation, 35, 75-80.

3. Gupta, M., Sinha, S. and Chandra, P. (1994) Uptake and toxicity of metals in Scirpuslacustris L. and Bacopamonnieri L. J. Environ. Sci. Health. 29, 2185-2202.

4. Irmak, S., Surucu, A.K. and Aydin, S. (2008) The effects of iron content of soils on the iron content of plants in the Cukurova region of Turkey. International journal of Soil Science, 3(3), 109-118.

5. Lindsay, W.L. and Norwell, W.R. (1978) Development of DTPA soil test for zinc, iron, manganese and copper. Soil Sci. Soc. Am. J. 42, 421-428.

6. Kabir, A. H., Begum, M.C., Haque, A., Amin, R., Swaraz, A.M., Haider, S.A., Paul, N.K. and Hossain, M.M. (2016)Genetic variation in Fe toxicity tolerance is associatedwith the regulation of translocation and chelation of iron along with antioxidant defence in shoots of rice.Functional Plant Biology, doi: 10.1071/FP16068.

7. Mehraban, P., Zadeh, A.A. and Sadeghipour, H.R. (2008) Iron toxicity in rice (Oryza sativa L.) under different potassium nutrition. Asian Journal of Plant Science, 7,251-259.

8. Panda, B.B., Sharma, S., Mohapatra, P.K. and Das. A. (2016) Iron homeostasis in tropical indica rice (Oryza sativa L.) cultivars having contrasting grain iron concentration. J. Plant Biochem. Biotechnol. doi: 10.1007/s13562-016-0350-1.

9. Panda, S.K. and Matsumoto, H. (2010) Changes in antioxidant gene expression and induction of oxidative stress in pea (Pisumsativum L.) under Al stress. Biometals,23,753-762. 
10. Pooladvand, S., Ghorbanli, M. and Farzami, S.M. (2012) Effect of various levels of iron on morphological, biochemical and physiological properties of Glycine max var. Pershing. Iranian Journal of Plant Physiology, 2(4), 531-538.

11. Sahrawat, K.L. (2005) Iron toxicity in wetland rice and the role of other nutrients. J. Plant Nutr. 27, 1471-1504.

12. Shi, Y., Dong, S., Liu, Z., Yi, K., Wang, J., Zhu, C. and Wang, F. (2016) Effect of exogenous ferrous sulfate treatment on edible rice. Am. J. Food. Technol. 11,165-170.

13. Sinha, S., Gupta, M. and Chandra, P. (1996) Bioaccumulation and biochemical effects on mercury in the plant Bacopamonnieri (L.). Environ. Toxicol. Water Qual. 11, 105-112.

14. Snowden, R. and Wheeler, B.D. (1995) Chemical changes in selected wetland plant species with increasing $\mathrm{Fe}$ supply, with specific reference to root precipitates and Fe tolerance. New Phytologist, 131, 503-520.

15. Taylor, G.J., Crowder, A.A. and Rodden, R. (1984) Formation and morphology of an iron plaque on the roots of Typhalatifolia L. grown in solution culture. Am. J. Bot. 71, 666-675. 